\title{
Remote sensing of terrestrial impact craters: The TanDEM-X digital elevation model
}

\author{
Manfred GOTTWALD ${ }^{1}$, Thomas FRITZ ${ }^{1}$, Helko BREIT ${ }^{1}$, Birgit SCHÄTTLER ${ }^{1}$, Alan HARRIS ${ }^{2}$ \\ ${ }^{1}$ Remote Sensing Technology Institute, German Aerospace Center, Oberpfaffenhofen, \\ D-82234 Wessling, Germany \\ 2Institute of Planetary Research, German Aerospace Center, Rutherfordstrasse 2, \\ D-12489 Berlin, Germany
}

\begin{abstract}
With the TanDEM-X digital elevation model (DEM) the terrestrial solid surface is globally mapped with unprecedented accuracy. TanDEM-X is a German X-band radar mission whose two identical satellites have been operated in single-pass interferometer configuration over several years. The acquired data are processed to yield a global DEM with $12 \mathrm{~m}$ independent posting and relative vertical accuracies of better than $2 \mathrm{~m}$ and $4 \mathrm{~m}$ in moderate and mountainous terrain, respectively. This DEM provides new opportunities for space-borne remote sensing studies of the entire sample of terrestrial impact craters. In addition, it represents an interesting repository to aid in the search for new impact crater candidates. We have used the TanDEM-X DEM to investigate the current set of confirmed impact structures. For a subsample of the craters, including small, mid-sized and large structures, we compared the results with those from other DEMs. This quantitative analysis demonstrates the excellent quality of the TanDEM-X elevation data. Our findings help to estimate what can be gained by using the TanDEM-X DEM in impact crater studies. They may also be beneficial for identifying regions and morphologies where the search for currently unknown impact structures might be most promising.
\end{abstract}

\section{INTRODUCTION}

Interplanetary spaceflight over the past 50 years has shown that impact craters are abundant on large and small solid bodies throughout the Solar System. Today we know that the phenomenon of collisions is a fundamental process in the history of the Solar System, having played the major role in forming the planets. Collisions of asteroids and comets with the Earth have taken place frequently over geological history and probably contributed to the development of life. In contrast, later impacts of asteroids and comets most likely played a role in mass extinctions and now present a scientifically well-founded threat to the future of our civilization. With the exception of our own planet, orbiting platforms or spacecraft on fly-by missions, equipped with remote sensing instruments, are the only means of gathering information about impacts on extraterrestrial solid bodies on a large scale. In the case of the Earth, candidate impact craters can be studied in situ with shock-metamorphic effects, if present, yielding final confirmation of the impact origin of a candidate structure. However, remotesensing data may offer significant support for such investigations.

The view from space-borne sensors allows access to remote areas. For impact structures, which cannot be explored by fieldwork because of their location, basic properties can be derived from remote sensing data. Prior studies from low-Earth orbit may provide geological context to facilitate preparation of on-site campaigns for maximum scientific return. In addition, the investigation of certain structures via remote sensing could deliver information not obtainable with geological fieldwork, for example imaging in ultra-violet to infrared wavelengths and microwave (radar) bands, or generation of elevation information. An appropriate design of the corresponding field-of-view 
PostPrint Version: Meteoritics \& Planetary Science, 52/7, 2017

allows coverage of even large areas on short timescales. Finally, remotely sensed data useful in the search for new impact crater candidates are readily accessible nowadays via data repositories.

One field where space-borne remote sensing of the Earth excels is in the provision of accurate elevation information on a global scale. A digital elevation model (DEM) can be derived from optical stereo pairs, altimeter measurements, or radar data obtained in interferometric mode. While optical sensors require a cloud free, transparent atmosphere, and altimeters may lack high resolution or fail to provide sufficient coverage, Synthetic Aperture Radar (SAR) interferometry is not compromised by such effects. Features introduced by the SAR method and its interferometric application can be minimized through an appropriate mission design together with careful calibration and DEM extraction during data processing.

In the 1990's exploitation of SAR interferometry became possible with the launch of the European ERS-1 and ERS-2 satellites in 1991 and 1995, respectively (Hartl et al. 1993). Both hosted a C-band SAR. The platforms could be operated as a repeat-pass interferometer with the interferometric acquisitions being separated by 1 day. The ERS satellites had demonstrated that SAR interferometry can be a powerful tool for mapping the terrestrial topography.

The first space mission with the objective to derive a DEM by means of SAR interferometry took place in the period 11-22 February 2000. The Shuttle Radar Topography Mission (SRTM), a joint project of NASA, DLR and ASI (the US, German and Italian Space Agencies, respectively), acquired interferometric data of the land surfaces within reach of the selected Shuttle orbit. It employed two radar sensors: a C-band SAR at a wavelength of $\lambda=5.6 \mathrm{~cm}$ and a swath width of $225 \mathrm{~km}$ together with an X-band SAR at $\lambda=3.1 \mathrm{~cm}$ and a swath width of $50 \mathrm{~km}$. With a second receiving antenna for both bands at the end of a $60 \mathrm{~m}$ boom for the duration of the mission, SRTM operated as a single-pass interferometer. The data from both sensors were processed to yield two DEMs. The Cband DEM was originally generated with an independent posting, equivalent to pixel spacing, of 3" (90 $\mathrm{m}$ at the equator) for the entire globe between latitudes of $56^{\circ} \mathrm{S}$ and $60^{\circ} \mathrm{N}$ for non-US regions and of $30 \mathrm{~m}$ for US territory. Meanwhile the 1" SRTM C-band DEM is also available outside the US. The X-band DEM had an independent posting of only $30 \mathrm{~m}$. However its reduced swath introduced regular data gaps. At the equator the X-band-derived DEM exhibited a separation of $\sim 160 \mathrm{~km}$ in adjacent orbits; around the northern and southern orbital turning points the separation vanished and provided some overlap. At the time of their generation the SRTM DEMs were the most accurate large-scale elevation models (Rabus et al. 2003).

\section{TANDEM-X DEM GENERATION}

When TanDEM-X, the TerraSAR-X add-on for Digital Elevation Measurement mission had been initiated, the goal was to generate a global terrestrial elevation model with a significant improvement in spatial sampling and elevation accuracy as compared to the SRTM DEM. Details about the mission can be found in, e.g., Krieger et al. (2007, 2013). Here we provide only a brief summary relevant to the application of the TanDEM-X DEM to impact crater studies.

The TanDEM-X mission uses two identical X-band radar satellites (Fig. 1), TerraSAR-X (TSX) and TanDEM-X (TDX). TSX was launched on 15 June 2007. For about 3 years it acquired data as an individual X-band mission until it was joined by the TDX platform on 21 June 2010. After successful commissioning of TDX, both satellites began to operate in close formation with combined data acquisitions being performed as a large single-pass interferometer (Table 1). It was primarily operated in bi-static mode where one satellite provided the microwave illumination of the Earth's surface and both satellites simultaneously received the radar echoes. A novel approach was a dedicated inter-satellite link for the synchronization of the phase of the two independent oscillators, required for modulation and demodulation of the radar pulses. This was a prerequisite for a precise calibration of the sensors which reduced errors in interferometric processing to a minimum. The 
PostPrint Version: Meteoritics \& Planetary Science, 52/7, 2017

challenging DEM requirements could only be achieved by selecting baselines, i.e. inter-satellite distances, of the order of 200-500 m. These had to be known with a precision of at most a few millimeters. The formation flying of both satellites was fully configurable from ground thus permitting data acquisition in various viewing geometries as required by DEM generation.

Measurements for DEM data takes occurred in a phased approach over a period of about 4.5 years. Firstly, in the timeframe December 2010 to March 2013, two global coverages were achieved. These were followed by two mappings of Antarctica, interleaved with gap filling activities and a period from August 2013 to April 2014 during which the satellite configuration was readjusted to allow imaging of difficult terrain with opposite viewing geometry. By early 2015, all acquisitions had been accomplished. In a single TanDEM-X orbit the maximum time devoted to DEM-related stripmap acquisitions with a swath width of $30 \mathrm{~km}$ amounted to about $300 \mathrm{sec}$, equivalent to a total orbital length of $2250 \mathrm{~km}$. These data were divided into individual scenes of $30 \times 50 \mathrm{~km}^{2}$ extent, each of which was processed to yield a so-called Raw DEM. About 570000 overlapping Raw DEMs have been generated from all acquisitions in single-pass interferometer configuration.

Each Raw DEM is the result of the interferometric processing chain which consists of several steps. They include focusing of the SAR image, co-registration of the two channels, generation of the interferogram and unwrapping the ambiguous phase with the conversion of phase to height (Rossi et al. 2012). Despite being the result of a single coverage, the precision achieved in a Raw DEM comes very close to that required for the final TanDEM-X DEM. In particular, the relative height accuracy approaches the required final DEM value of better than $2 \mathrm{~m}$ and for $90 \%$ of all Raw DEMs the absolute height error lies within $\pm 10 \mathrm{~m}$ of SRTM/ICESat reference points already prior to calibration (Zink 2015). In order to facilitate mosaicking, Raw DEMs are spatially oversampled by a factor of 2, i.e. their pixel posting amounts to $\sim 6 \mathrm{~m}$. However, several systematic inaccuracies may still persist (Gruber et al. 2012), for example limited regions with incorrect heights due to phase unwrapping errors, tilts across the scene of at most a few centimeters per km or occasional height offsets of up to several tens of meters (Zink 2015).

All these inconsistencies are reduced to a minimum in the mosaicking of the individual Raw DEMs to form the final DEM. This processing involves novel approaches in fusing multiple acquisitions from different mission phases, i.e. two nominal coverages of all land masses, difficult terrain sensed with crossing acquisitions, desert areas additionally observed with steeper incidence angles and large forest together with mountainous regions reacquired with a larger Height of Ambiguity to alleviate phase unwrapping (Gruber et al. 2015). As a result, the final Tandem-X DEM complies with the requirements as listed in Table 2.

\section{TANDEM-X DEM STATUS}

The final TanDEM-X DEM is organized in tiles of width $1^{\circ}$ in latitude and $1^{\circ}, 2^{\circ}$ or $4^{\circ}$ in longitude, depending on latitude. The entire terrestrial land mass of $\sim 150 \times 10^{6} \mathrm{~km}^{2}$ is covered by about 20000 tiles. At the time of writing, more than $90 \%$ of the DEM tiles have been processed. Except for archipelagos and small regions in difficult terrain such as large forests or deserts, the only major area still under production is Antarctica. Validation of the DEM by using ICESat and SRTM reference data showed that $98.6 \%$ of all data achieve the specification for the relative height accuracy. The absolute vertical precision even exceeds the requirement significantly and lies about one order of magnitude below $\pm 10 \mathrm{~m}$ for $90 \%$ of the data (Zink, private communication). In comparison to the SRTM DEM the improvement is due not only to much tighter specifications for the absolute and relative vertical accuracies together with the spatial coverage and sampling, but also to a significant reduction of data voids. Significant voids can exist in the SRTM DEM in difficult 
PostPrint Version: Meteoritics \& Planetary Science, 52/7, 2017

terrain where interferometric DEM generation was hampered by shadow effects and low SNR or was even impossible due to missing acquisitions.

The final TanDEM-X DEM is scheduled to be completed in the $2^{\text {nd }}$ half of 2016. Quota-limited access to the DEM for scientific purposes will be granted via an Announcement of Opportunity (AO) issued by DLR. Detailed information about the TanDEM-X AO are provided by the TanDEM-X Science Server (TDX AO 2016).

\section{APPLYING THE TANDEM-X DEM TO IMPACT STRUCTURES}

As soon as the first Raw DEMs had been processed, we began analyzing their usefulness for impact crater investigations. Early results were based on a limited set of acquisitions after the first global coverage only, but already showed the superior quality of the DEM (Gottwald et al. 2015). Since then we have continuously extended our studies by widening the crater sample and increasing the DEM data to be accessed. In contrast to our initial work we now have access to the entire set of Raw DEMs which qualified for use as input to TanDEM-X DEM generation. Additionally, already available DEM tiles could also be used for the very large structures with diameters $>50 \mathrm{~km}$.

\section{From flat radar data to 3D models}

The DEM data of all impact structures have been subject to the same work flow. Fig. 2 illustrates the involved steps for the example of Ouarkziz (lat $=29^{\circ} 00^{\prime} \mathrm{N}$, long $=7^{\circ} 33^{\prime} \mathrm{W}$ ) in south-west Algeria as derived from a subset of a single Raw DEM. This 3.0-3.5 km wide eroded structure has rarely been the site of field work (Koeberl 1994). Only recently, Sahoui et al. (2014) and Sahoui and Belhai (2015) published new geological studies.

The TanDEM-X data were acquired on 18 September 2012 at 18:30:00 UTC in an ascending orbit. The Raw DEM delivery included the radar X-band amplitude signal strength and the digital elevation representing the ellipsoidal heights relative to the WGS84 ellipsoid in meters. Surfaces facing towards the right-looking radar antenna, i.e. with western orientation for an ascending orbit, appear bright in the radar map (Fig. 2a). Darker areas are regions with lower radar reflectivity, mainly caused by lower surface roughness. In the elevation map (Fig 2b), color coding provides information on the vertical dimension. Throughout our studies we have used artificial illumination with a Sun elevation of $45^{\circ}$ and a solar azimuth of $315^{\circ}$ when generating the hillshaded maps (Fig. 2C) from the DEMs. Combination of the hillshaded map with the DEM results in a nadir-looking 3D-type image (Fig. 2d). Superposition of this image on the radar amplitude signal generates a map in which surface texture, in addition to elevation information, can be inferred. Other hillshading methods, e.g. circular sunshading, or oblique 3D-views would deliver different results and might be the tools of choice when studying individual impact structures in detail.

\section{Comparison with existing DEMs}

To date we have analyzed the entire sample of confirmed impact structures displaying imprints in the surface topography, as listed in the Earth Impact Database (EID 2016) at the Planetary and Space Science Center of the University of New Brunswick, supplemented by Saqqar, a recently confirmed structure by Kenkmann et al. (2015). In order to demonstrate how morphological studies of impact craters can benefit from its high accuracy, we compared the TanDEM-X DEM for a subsample of them with other DEMs from several sources. The specifications of the selected DEMs are listed in Table 3.

SRTM1 is the recently published global DEM between $56^{\circ} \mathrm{S}$ and $60^{\circ} \mathrm{N}$ with $1^{\prime \prime}$ pixel spacing, equivalent to about $30 \mathrm{~m}$ at the equator, derived from C-band data acquired during the 10-day Shuttle Radar Topography Mission in February 2000. As for the TanDEM-X DEM it is based on the 
method of single-pass SAR interferometry. ASTER GDEM V2 refers to the second version of the global DEM extracted from stereo-optical imagery obtained with the Advanced Spaceborne Thermal Emission Reflection Radiometer (ASTER) onboard NASA's Terra platform (Abrams et al. 2015). DGM10 stands for a DEM provided by the Bundesanstalt für Kartographie und Geodäsie (BKG), the national service provider for geomatics in Germany. This DEM is compiled using data from federal geodetic services with laser scanning being one of the measurement techniques (BKG 2015). The DEM for the Meteor crater in Arizona is derived from the LiDAR point cloud which was obtained during a campaign of the National Center for Airborne Laser Mapping (NCALM) in 2010 (LPI 2012). Both SRTM1 and ASTER GDEM V2 have been obtained from USGS' Earth Explorer site. DGM10 was received on request from BKG and the Meteor crater LiDAR NCALM-DEM has been extracted from LPI's dedicated "Barringer Crater Guidebook" website. The selected DEMs differ in horizontal and vertical datum. Where required, we transferred them to WGS84 (horizontal) and EGM96 (vertical).

Various studies have verified the quality of the spaceborne DEMS SRTM1 and ASTER GDEM V2 (Gesch 2013 and references therein). On a global scale the specified performance as listed in Table 3 is usually met or even exceeded. However, depending on the type of the sensed scene, certain features and artefacts might be present which require careful consideration. DEMs extracted from SARinterferometric data can exhibit data voids caused by steep terrain or areas with very low radar backscatter. The yearlong TanDEM-X mission could compensate for this by modifying the satellite configuration in orbit or by repeated acquisitions while the short SRTM flight had no such options. Voids in the ASTER DEM occur mainly because of cloud coverage. In addition errors and artefacts may be present, particularly in smooth scenes where photogrammetric patterns were difficult to match (Crippen 2010). The $2^{\text {nd }}$ version of the ASTER DEM provides for an improvement compared to its $1^{\text {st }}$ version but introduces higher elevation noise which can become obvious in certain applications such as, e.g., hillshaded relief maps (Tachikawa et al. 2011).

TanDEM-X, SRTM and ASTER data sets have "first-return" characteristics, i.e. they sense the elevation where backscatter or reflection occurs. In vegetated areas this is at the top of the canopy with C-band radar penetrating somewhat deeper into the vegetation layer than the X-band. Therefore the elevation in the corresponding DEM reflects the Earth's surface and not "bare Earth". Comparisons with DEMs from LiDAR measurements have to take this into account.

The pixel spacing of the five DEMs used here differ by a factor of 30 . Often pixel spacing is misinterpreted in terms of spatial resolution. Several investigations have shown that the actual spatial resolution is coarser than the independent pixel posting and might depend on the elevation characteristics of the terrain (Gesch 2013 and references therein). The validation study for ASTER derived a spatial resolution of 70-82 $\mathrm{m}$ for GDEM V2 and claimed similar values for SRTM1, i.e. a factor 2.5 larger than the corresponding pixel spacing (Tachikawa et al. 2011). An earlier investigation of a site in Nevada resulted in a higher resolution for SRTM1 of only 1.6 pixels, i.e. $\sim 50 \mathrm{~m}$ (Pierce et al. 2006).

For all our comparisons described below we applied an identical work flow. The extracted DEM data were used "as is", i.e. no additional processing to improve data performance was carried out. This allowed direct intercomparison of the inherent data quality. A hillshaded color coded DEM yielded the nadir-looking 3D-type image. Color coding was identical for all maps with minimum and maximum elevation corresponding to dark green and grey-white hues, respectively. This provided for identical "looks", a prerequisite to judge the DEMs qualitatively by visual inspection. In order to maintain clarity, in the figures we provide the color scale only for the TanDEM-X map. The reader is referred to Table 4 for the applicable minimum and maximum elevations for the other crater displays. For each structure and available DEM we performed a statistical analysis yielding minimum, maximum and mean elevation values in the particular scenes (Table 4). Except for potential outliers the derived elevations were compliant with the vertical accuracies of the DEMs. This permitted a quantitative comparison of the quality of the DEM around the site of the impact structure. For obtaining a more specific view of 
PostPrint Version: Meteoritics \& Planetary Science, 52/7, 2017

how the individual DEMs reflect the morphology of particular impacts we generated elevation profiles. They demonstrated how the performance achieved in each DEM allows retrieving reliable crater parameters, e.g. rim and floor height.

\section{Meteor Crater}

Meteor crater (lat $=35^{\circ} 02^{\prime} \mathrm{N}$, long $=111^{\circ} 01^{\prime} \mathrm{W}$ ) in Arizona is one of the best characterized impact structures. The high resolution DEM based on the LiDAR point cloud covers a $5 \mathrm{~km}$ wide square area centered on the crater with coverage of its ejecta blanket. It serves as a superior reference for the TanDEM-X DEM. Fig 3 shows the four hillshaded color-coded DEMs of Meteor crater. In all cases scaling was adjusted to an image size equivalent to a $100 \%$ crop of the TanDEM-X Raw DEM. This required NCALM (Fig. 3a) to be downsized by a factor of 6 . The full resolution of the NCALM map can be inferred from the inset which shows fine structure at full resolution in the gully system close to the southwest rim. The TanDEM-X map (Fig. 3b) is from a single acquisition. Even though some elevation noise is still present in the flat arid surroundings, crater details are clearly visible. SRTM (Fig. 3c) and ASTER (Fig. 3d) had to be enlarged by a factor of 5 . The SRTM DEM appears as a smoothed, lowresolution version of TanDEM-X, as expected from the difference in pixel spacing and vertical resolution. The ASTER DEM is scattered with artefacts and high elevation noise, e.g. the northbound Chavez Pass Road west of the crater, which is obvious in the NCALM DEM, has a canyon-like structure in the ASTER map.

Spatial statistics for the 4 DEMs of Fig. 3 are listed in Table 4. Since the Meteor crater site is an arid, topographically uncomplicated area, even the minimum and maximum elevations, which could be spoiled by outliers, agree well considering the specified vertical accuracies. The mean elevations in the scene are very similar in the cases of NCALM and SRTM while ASTER lies $3.8 \mathrm{~m}$ below the NCALM value. The TanDEM-X DEM mean elevation is $2.8 \mathrm{~m}$ lower than NCALM's. However, given the fact that the TanDEM-X DEM is a single Raw DEM without a final DEM elevation calibration, this difference can be considered more than acceptable. The relation between the 4 DEMs has additionally been analyzed by comparing elevation profiles. We extracted a west-east transect through the scene. The four profiles are given in Fig. 4a. The higher elevation noise in the ASTER DEM is immediately apparent. Deviations between NCALM and SRTM are obvious around the rim and the steep inward slopes where TanDEM-X agrees well with NCALM. Figure $4 \mathrm{~b}$ shows that the negative difference between TanDEM-X and NCALM persists throughout the profile with only slightly higher absolute values at the rim and the steeper inward walls. As a consequence, the slope along the profile, expressed as $\Delta$ elevation/ $\Delta$ distance in \%, agrees well between NCALM and TanDEM-X (Fig. 4c) indicating that the TanDEM-X DEM not only provides reliable elevations but also reflects the true shape of the structures.

\section{Very Small Craters}

For the subsample of young, very small impact craters with diameters of $<1000 \mathrm{~m}$ the spatial sampling of spaceborne DEMs poses a challenge. They can be unambiguously distinguished in elevation data only when located in suitable terrain. An arid, rocky environment favors their detection while vegetation and sand covered surfaces tend to mask them, particularly in DEMs based on radar technology. We have explored a number of small craters with TanDEM-X. Among them, the largest bowl-shape depressions of the crater fields Morasko (lat $=52^{\circ} 29^{\prime} \mathrm{N}$, long $=16^{\circ} 54^{\prime} \mathrm{E}$ ) in Poland and Kaalijärv (lat $=58^{\circ} 24^{\prime} \mathrm{N}$, long $=22^{\circ} 40^{\prime} \mathrm{E}$ ) in Estonia, both located in forested areas, have diameters of $\sim 100 \mathrm{~m}$ and are not detectable with current data. Since radar X-band backscatter occurs from the tree canopy, vegetation shields both structures from being interferometrically sensed. Wabar (lat = $21^{\circ} 30^{\prime} \mathrm{N}$, long $=50^{\circ} 28^{\prime} \mathrm{E}$ ) on the Arabian Peninsula is located in the Rub' al Khali sand desert. Since its discovery in 1932, the largest crater has been gradually filled by migrating sand dunes (Gnos et al. 
PostPrint Version: Meteoritics \& Planetary Science, 52/7, 2017

2013). Due to its present shallow depth, combined with the low X-band backscatter in sand, the structure, although $110 \mathrm{~m}$ in diameter, is not detectable with TanDEM-X. However, Veevers (lat = $22^{\circ} 58^{\prime} \mathrm{S}$, long $=125^{\circ} 22^{\prime} \mathrm{E}$ ) in Western Australia with a diameter of $80 \mathrm{~m}$, and Kamil (lat $=22^{\circ} 01^{\prime} \mathrm{N}$, long $=26^{\circ} 05^{\prime} \mathrm{E}$ ) in Egypt with a size of only $45 \mathrm{~m}$, can be identified in TanDEM-X hillshaded maps. The latter craters are both located in arid rocky regions where backscattered radar signals are less hampered by low SNR.

Figures 5 and 6 demonstrate TanDEM-X' capabilities for studying small structures. We selected three cases covering the diameter range $<1000 \mathrm{~m}$ : Henbury, Amguid and Wolfe Creek. While Fig. 5 displays these structures embedded in a $5 \times 5 \mathrm{~km}^{2}$ scene, Fig. 6 provides close-ups from the TanDEM$X$ maps to illustrate the achievable details in crater morphology. The Henbury crater field (lat = $24^{\circ} 34^{\prime} \mathrm{N}$, long $=133^{\circ} 08^{\prime} \mathrm{E}$ ) in Australia's Northern Territory consists of about 13-14 craters, scattered over an area of $\sim 0.5 \mathrm{~km}^{2}$. The largest (no. 7) is oval-shaped with a maximum length of about $180 \mathrm{~m}$ (Milton 1968). In the TanDEM-X hillshaded DEM (Fig. 5a) this structure is clearly visible. Even smaller craters can be discerned, e.g. the only $60 \mathrm{~m}$ wide no. 4 in Milton's list (Fig. 6a). For crater no. 7 DEM data suggest a length of 170-180 m and a depth of 10-15 m in good agreement with Milton's findings. In the SRTM DEM (Fig. 5d) a small local depression can be seen at the location of the main crater but without an outline of the oval shape. Similar depressions scattered throughout the scene are unrelated to Henbury but caused by noise. The ASTER DEM (Fig. $5 \mathrm{~g}$ ) shows even less traces of Henbury. Amguid (lat $=26^{\circ} 05^{\prime} \mathrm{N}$, long $=4^{\circ} 23^{\prime} \mathrm{E}$ ) in southern Algeria, about $300 \mathrm{~km}$ north of Tamanarasset, is a well preserved simple crater with a diameter of $450 \mathrm{~m}$ and an elevated rim up to $50 \mathrm{~m}$ high situated on the Immidir plateau, close to the eastern escarpment and the wadi Oued Tafrakrek (Reimold and Koeberl 2014). Due to filling with eolian deposits and silts, the crater floor appears bright in optical imagery, but shows very low backscatter signal in the radar X-band. This causes some elevation noise in the TanDEM-X DEM (Fig. 5b and 6b). The derived diameter of $460 \mathrm{~m}$ and maximum rim height of about $40-50 \mathrm{~m}$ are compliant with the morphometric parameters provided in Reimold and Koeberl (2014). The SRTM DEM (Fig. 5e) displays a central uplift in Amguid, an artefact probably caused by the crater's floor low radar backscatter signal. The ASTER scene of Amguid (Fig. 5h) appears slightly more resolved than SRTM but the crater's circular shape as known from aerial photography and reflected in the TanDEM-X map is not displayed. Wolfe Creek (lat = $19^{\circ} 10^{\prime} \mathrm{S}$, long $=127^{\circ} 48^{\prime} \mathrm{E}$ ) is located on the eastern edge of Western Australia's Great Sandy Desert. The rim has an elongated shape of $935 \times 825 \mathrm{~m}$ with a mean diameter of $880 \mathrm{~m}$ and stands about 50 $\mathrm{m}$ above the crater floor (Shoemaker et al. 2005). Around the center of the crater floor vegetation exists. Its densely populated part with larger trees forms a ring which can be recognized in the TanDEM-X map (Fig. 6c). The rest of the scene imaged in Fig. $5 c$ is rather flat. It appears only slightly structured by eolian sand dunes. Both the elongated shape and the average rim elevation above the crater floor can be retrieved with good precision. TanDEM-X yields approximate parameters of $940 \times$ $825 \mathrm{~m}$ and 40-50 m. Because of Wolfe Creek's size, also SRTM (Fig. 5f) and ASTER (Fig. 5i) clearly map this structure. However, their coarser spatial resolutions, coupled with higher elevation noise, prevent the retrieval of fine structure. The statistics summary for the three craters listed in Table 4 shows agreement within the specified accuracies of the corresponding DEMs.

Craters with diameters $<1 \mathrm{~km}$ are particularly interesting. Estimates by Hergarten and Kenkmann (2015) of the number of terrestrial impact structures still undiscovered indicate that the crater record on Earth is deficient in structures with diameters $<6 \mathrm{~km}$. About 340 structures may await discovery, with the largest fraction, i.e. 250, populating the regime $0.25-1 \mathrm{~km}$. Analysis of our small crater subsample shows that TanDEM-X can be regarded as a source for reliably identifying candidates in this size range. Therefore search algorithms might be successful provided the selected test area favors high-quality interferometric measurements. Candidates are usually found in remotely sensed datasets due to their circular shapes. For young craters the TanDEM-X DEM can display an obvious circular rim with elevated altitudes. In older and more degraded structures, circularity may be restricted to 
PostPrint Version: Meteoritics \& Planetary Science, 52/7, 2017

segments of the original rim or will appear in the form of drainage patterns. In all cases, however, the DEM search algorithms would yield only candidate discoveries and fieldwork is required for verification. Circularity is not a unique feature of impacts but may also identify intrusions, salt domes, volcanic calderas or sinkholes.

\section{Ries Crater}

Ries crater (lat $=48^{\circ} 53^{\prime} \mathrm{N}$, long $=10^{\circ} 37^{\prime} \mathrm{E}$ ) is a well-studied mid-size impact structure in Bavaria/Germany. In contrast to the craters from the arid sites analyzed so far, Ries is located in a welldeveloped, vegetated area. For DEM reference, we used DGM10. Since it has been derived from laser scanning, it represents "bare earth". Fig. 7a shows a mosaic of Raw DEMs centered on the Ries. The $24 \mathrm{~km}$ wide outer crater limit, which is inconspicuous in visible imagery, is clearly outlined. Both the crater floor and the hills of the surrounding Swabian Alb and Franconian Jura are dotted with forest patches which constitute the "first-return" for the X-band sensors. Even villages and roads can be spotted in the DEM. For comparison, Fig. 7b includes the hillshaded elevation map generated from DGM10. It appears flat where the TanDEM-X map displays tall vegetation, otherwise both maps agree remarkably well. For comparison with the SRTM and ASTER DEM we selected a $16 \times 9 \mathrm{~km}^{2}$ large area in the eastern Ries. It includes the Wennenberg as a mark of the inner ring, various forest patches and is cut through by the small Wörnitz river. In Fig. 8a this area is shown in full TanDEM-X resolution together with the SRTM (Fig. 8b) and ASTER (Fig. 8c) equivalents. The vertical resolution of the TanDEM-X DEM even permits identification of individual farmland detail. As in the previous cases SRTM and ASTER have lower spatial resolution. Where the TanDEM-X map indicates rather flat terrain, the ASTER DEM shows prominent artefacts. The vegetated and hilly character of the Ries region is presumably the cause for the larger differences observed in minimum and maximum elevations over the entire scene as listed in Table 4. The mean elevation is in good agreement between TanDEM-X and SRTM, with ASTER being considerably lower.

A west-east profile was retrieved spanning in total $33 \mathrm{~km}$. For the selected vertical scale, TanDEMX, DGM10 and SRTM are almost indistinguishable in the flat inner Ries. However, where taller vegetation, e.g. visible at distances slightly above $18 \mathrm{~km}$ and $24 \mathrm{~km}$, is detected by TanDEM-X and SRTM, the DGM10 model remains flat. At the crater rim and beyond differences become more pronounced due to the modulated terrain. The ASTER profile displays the largest scatter and, as already indicated by the mean value in Table 4, lies on average below the profiles of the other DEMs.

\section{High Latitude Craters}

More than 20\% of the confirmed and exposed impact structures have latitudes $>60^{\circ}$. ASTER provides the only global spaceborne DEM with narrow pixel posting covering these craters. An alternative to the ASTER DEM would be the pan-arctic elevation data which have been assembled under the auspices of the European Space Agency ESA in support of the PERMAFROST project. This activity generated a DEM between $55^{\circ}-83^{\circ} \mathrm{N}$ from various sources (Bartsch et al. 2012), including topographic maps of Russia (1:200.000) and Canada (1:250.000). The pixel posting is $90 \mathrm{~m}$ but because of the inputs, no quantitative accuracies are specified. For the Russian sector Strozzi and Santoro (2011) confirmed the high quality of this data set by visual inspection. The regional character, coupled with the much larger pixel posting and uncertain accuracies, however, prevented us from using the pan-arctic DEM in our comparison.

Beyenchime-Salaatin (lat $=71^{\circ} 03^{\prime} \mathrm{N}, 121^{\circ} 41^{\prime} \mathrm{E}$ ) and Popigai (lat $=71^{\circ} 39^{\prime} \mathrm{N}$, long $=111^{\circ} 11^{\prime} \mathrm{E}$ ) are two impact structures in northern Siberia. Beyenchime-Salaatin is described by Masaitis (1999) as a circular structure with a diameter of $8 \mathrm{~km}$, surrounded by a rim standing about $50-70 \mathrm{~m}$ above the crater floor. The TanDEM-X map (Fig. 10a) shows the structure as a distinct feature. The Beyenchime- 
PostPrint Version: Meteoritics \& Planetary Science, 52/7, 2017

Salaatin river and one of its tributaries cut through the southern and western rim sections. In the TanDEM-X data the crater shape appears slightly elongated at $7.8 \times 8.3 \mathrm{~km}$ with a maximum rim height of about $70 \mathrm{~m}$ as reported by Masaitis (1999). As already evident in the previous maps, the ASTER display (Fig. 10b) is affected by strong elevation noise and some artefacts. This erases all details of the drainage system and contributes to the large differences in minimum and maximum elevations as listed in Table 4. The mean elevation indicates that the ASTER DEM in that area falls more than 10 $\mathrm{m}$ below the TanDEM-X DEM. This is also apparent in the profiles (Fig. 12a). The surface topography is rather smooth at this latitude close to the tundra tree line as indicated by the TanDEM-X profile. The ASTER data exhibit the known elevation noise and lie constantly below the TanDEM-X curve.

With a diameter of about $100 \mathrm{~km}$ Popigai ranks among the largest impact structures (Deutsch et al. 2000). The TanDEM-X DEM for Popigai shown in Fig. 11a is a mosaic made from final DEM tiles. A wealth of fine structure can be discerned in the $150 \times 130 \mathrm{~km}^{2}$ large hillshaded map, which provides a clear view of the central circular depression of $70 \mathrm{~km}$, together with the concentric structural features of the crater area. Many lakes and rivers contribute to the drainage system. Most prominently the Popigai river winds through the lowest part of the crater northward with the main tributaries Rassokha and Fomich joining at the northern edge. The corresponding ASTER map in Fig. 11b displays considerable elevation noise coupled with certain artefacts. The mean elevations in Table 4 show that the ASTER values are lower by several meters, which is similar to our findings for Beyenchime-Salaatin, located at a similar latitude only $380 \mathrm{~km}$ to the east. The characteristics of the Popigai profiles (Fig. 12b) resemble those for Beyenchime-Salaatin: large-scale features agree reasonably well in both transects but the ASTER values are lower and much noisier.

\section{CONCLUSIONS}

Our qualitative and quantitative analyses have demonstrated that the TanDEM-X DEM is well suited for morphological studies of terrestrial impact craters. The global coverage provides access to all currently confirmed structures, even those beyond the Arctic Circle. The high absolute and relative vertical precision, combined with the high spatial sampling, allows mapping in great detail. Even when applying a standard work flow, the resulting charts provide accurate insights into the topography of the impact structures. The results presented for a subsample of craters ranging from some $100 \mathrm{~m}$ to $100 \mathrm{~km}$ in diamter illustrated the improvement in comparison to the other existing spaceborne global DEMs, SRTM1 and ASTER GDEM V2.

Our analysis indicates a lower limit of some 50-100 $\mathrm{m}$ for the detectability of impacts in the DEM in suitable terrain. Mapping structures of about $100 \mathrm{~m}$ diameter already provides reliable morphometric properties. This is also the size domain which might be of greatest interest in a search for new impact candidates in the DEM data since it represents the size range where the deficit in the terrestrial impact crater record seems to be most pronounced. With the knowledge gained from our investigations of the sample of confirmed impact structures, one of the next steps will be the development of strategies and procedures to search for promising impact structure candidates that may motivate subsequent fieldwork.

\section{ACKNOWLEDGEMENTS}

The authors thank Silke Kerkhoff and Thomas Busche for their continuous effort in supporting TanDEM-X data access and Wael Abdel Jaber for his patient support in using suitable software analysis tools. Finally we also like to express our thanks to both referees. Because of their comments this paper has improved considerably. The TanDEM-X project is partly funded by the German Federal Ministry for Economics and Technology (Foerderkennzeichen 50 EE 1035). 
PostPrint Version: Meteoritics \& Planetary Science, 52/7, 2017

\section{REFERENCES}

Abrams, M., Tsu, H., Hulley, G., Iwao, K., Pieri, D., Cudahy, T., Kargel, J. 2015. The Advanced Spaceborne Thermal Emission and Reflection Radiometer (ASTER) after fifteen years: Review of global products. International Journal of Applied Earth Observation and Geoinformation 38:292301.

Bartsch, A., Duguay, C., Elger, K., Glira, P., Hachem, S., Heim, B., Hese, S., Melzer, T., Mistelbauer, T., Naeimi, V., Notegger, C., Paulik, C., Park, S.E., Reschke, J., Ressl, C., Pöcking, S., B., Sabel, D., Schlaffer, S., Schwamborn, G., Soliman, A., Strozzi, T., Urban, M., Voltersen, M., Wagner, W., Wiesmann, A., Zwieback, S. 2012. ESA DUE Permafrost Final report v2. Vienna, Vienna University of Technology (Institute of Photogrammetry and Remote Sensing).

Bundesamt für Kartographie und Geodäsie (BKG). 2015. Digitales Geländemodell Gitterweite $10 \mathrm{~m}$ - DGM10. https://www.bkg.bund.de/DE/Produkte-und-Services/Shop-und-Downloads/DigitaleGeodaten/Gelaendemodelle/Deutschland/deutschland.html. Accessed June 7, 2016.

Crippen, R. E. 2010. Global topographical exploration and analysis with the SRTM and ASTER elevation models. In Elevation Models for Geoscience, edited by Fleming, C., Giles, J. R. A., Marsh, S. H. GSL Special Paper 345. London: Geological Society of London, pp.5-15.

Deutsch, A., Masaitis, V. L., Langenhorst, F., and Grieve, R. A. F. 2000. Popigai, Siberia - well preserved giant impact structure, national treasury, and world's geological heritage. Episodes 23:3-11.

Earth Impact Database (EID). 2016. http://www.passc.net/EarthlmpactDatabase/. Accessed June 7, 2016.

Gesch, D B. 2013.Global digital elevation model development from satellite remote-sensing data. In Advances in Mapping fromRemote Sensing Imagery: Techniques and Applications, edited by Yang, X., Li, J. Boca Raton, Florida: CRC Press, pp. 91-117.

Gnos, E., Hofmann, B. A., Halawani, M.A., Tarabulsi, Y., Hakeem, M., Al Shanti, M., Greber. N. D., Holm, S., Alwmark, C., Greenwood, R. C., and Ramseyer, K. 2013. The Wabar impact craters, Saudi Arabia, revisited. Meteoritics \& Planetary Science 48:2000-2014.

Gottwald, M., Fritz, T., Breit, H., Schättler, B, and Harris, A. 2015. Mapping terrestrial impact craters with the TanDEM-X digital elevation model. In Large Meteorite Impacts and Planetary Evolution V, edited by Osinski, G. R., and Kring, D. A. GSA Special Paper 518. Boulder, Colorado: Geological Society of America, pp. 177-211.

Gruber, A., Wessel, B., Huber, M., and Roth, A. 2012. Operational TanDEM-X DEM calibration and first validation results. ISPRS Journal of Photogrammetry and Remote Sensing 73:39-49.

Gruber, A., Wessel, B., Martone, M., Roth, A. 2015. The TanDEM-X DEM Mosaicking: Fusion of Multiple Acquisitions Using InSAR Quality Parameters. IEEE Journal of Selected Topics in Applied Earth Observations and Remote Sensing in print:11p.

Hartl, P., Reich, M., Thiel, K.-H., and Xia, Y. 1993. SAR interferometry applying ERS-1: Some preliminary test results. Proceedings, $1^{\text {st }}$ ERS-1 Symposium, pp. 219-222.

Hergarten, S. and Kenkmann, T. 2015. The number of impact craters on Earth: Any room for further discoveries? Earth and Planetary Science Letters 425:187-192.

Kenkmann, T., Afifi, A.M., Stewart, S.A., Poelchau, M.H., Cook, D., and Neville, A.S., 2015. Saqqar: A $34 \mathrm{~km}$ diameter impact structure in Saudi Arabia. Meteoritics \& Planetary Science 50:19251940.

Koeberl, C. 1994. African meteorite impact craters: characteristics and geological importance. Journal of African Earth Sciences 18:263-295.

Krieger, G., Moreira, A., Fiedler, H., Hajnsek, I., Werner, M., Younis, M., and Zink, M. 2007 TanDEM-X: A Satellite Formation for High-Resolution SAR Interferometry. IEEE Transactions on Geoscience and Remote Sensing 45:3317-3341. 
Krieger, G., Zink, M., Bachmann, M., Bräutigam, B., Schulze, D., Martone, M., Rizzoli, P., Steinbrecher, U., Antony, J. W., De Zan, F., Hajnsek, I., Papathanassiou, K., Kugler, F., Rodriguez, C., Younis, M., Baumgartner, S., López-Dekker, P., Prats, P., Moreira, A. 2013. TanDEM-X: A radar interferometer with two formation-flying satellites. Acta Astronautica 89:83-98.

Lunar and Planetary Institute (LPI). 2012. Airborne LiDAR of Meteor Crater and the Surrounding Landscape. $\quad$ http://www.Ipi.usra.edu/publications/books/barringer crater guidebook/LiDAR/. Accessed June 7, 2016.

Masaitis, V.L. 1999. Impact structures in northeastern Eurasia: The territories of Russia and adjacent countries. Meteoritics \& Planetary Science 34:691-711.

Milton, D. J. 1968, Structural Geology of the Henbury Meteorite Craters, Northern Territory, Australia. Contributions to Astrogeology, U.S. Geological Survey Professional Paper 599-C. Washington, D.C.: United States Government Printing Office. 17p.

Pierce, L., Kellndorfer, J., Walker, W., and Barros, O. 2006. Evaluation of the Horizontal Resolution of SRTM Elevation Data. Photogrammetric Engineering and Remote Sensing 72:1235-1244.

Rabus, B., Eineder, M., Roth, A., Bamler, R. 2003. The shuttle radar topography mission - a new class of digital elevation models acquired by spaceborne radar. ISPRS Journal of Photogrammetry and Remote Sensing 57:241-262.

Reimold, W. U. and Koeberl, C. 2014 Impact structures in Africa: A review. Journal of African Earth Sciences 93:57-175.

Rossi, C., Rodriguez Gonzalez, F., Fritz, T., Yague Martinez, N., and Eineder, M. 2012 TanDEM-X calibrated Raw DEM generation. ISPRS Journal of Photogrammetry and Remote Sensing 73:1220.

Sahoui, R., Belhai, D., Amrouche, F. 2014. Field Studies of the Ouarkziz Impact Structure, Algeria (abstract). $77^{\text {th }}$ Annual Meteoritical Society Meeting. LPI contribution 1800:5105.

Sahoui, R., Belhai, D. 2015. Ouarkziz Impact Structure, Algeria: Preliminary Petrographic and Geochemical Results (abstract). 78 $8^{\text {th }}$ Annual Meteoritical Society Meeting. LPI contribution 1856:5081.

Shoemaker, E. M., Mcdonald, F. A., and Shoemaker, C. S. 2005. Geology of five small Australian impact craters. Australian Journal of Earth Sciences 52:429-444.

Strozzi, T., Santoro, M. 2011. Pan-Arctic DEM V1 product guide. Vienna, Vienna University of Technology (Institute of Photogrammetry and Remote Sensing)

Tachikawa, T., Kaku, M., Iwasaki, A., Gesch, D., Oimoen, M., Zhang, Z., Danielson, J., Krieger, T., Curtis, B., Haase, J., Abrams, M., Crippen, R., Carabajal, C. 2011. Aster Global Digital Eleveation Model Version 2 - $\quad$ Summary of http://www.jspacesystems.or.jp/ersdac/GDEM/ver2Validation/Summary_GDEM2_validation report final.pdf, Accessed June 7, 2016.

TanDEM-X Science Server Announcement of Opportunity (TDX AO). 2016. TanDEM-X Digital Elevation Models Announcement of Opportunity \& Proposal Call. https://tandemx-science.dlr.de. Accessed September 6, 2016.

Zink, M. 2015 TanDEM-X Mission Status. The International Archives of the Photogrammetry, Remote Sensing and Spatial Information Sciences XL-7M3:1345-1352. 
PostPrint Version: Meteoritics \& Planetary Science, 52/7, 2017

Table 1: TanDEM-X orbital parameters

\begin{tabular}{ll}
\hline \hline Parameter & Requirement \\
\hline Type & polar sun-synchronous \\
Local Time Ascending Node Crossing & $18: 00$ (dusk/dawn) \\
Altitude & $514.8 \mathrm{~km}$ \\
Orbital Period & $95 \mathrm{~min}$ \\
Perigee-Apogee & $2 \mathrm{~km}$ \\
Inclination & $97.44^{\circ}$ \\
\hline
\end{tabular}

Table 2: TanDEM-X DEM specifications

\begin{tabular}{ll}
\hline \hline Parameter & Requirement \\
\hline Independent posting (pixel) & $12 \mathrm{~m}$ \\
Absolute vertical accuracy $(90 \%$ linear error) & $<10 \mathrm{~m}$ \\
Relative vertical accuracy & $(90 \% \quad<2 \mathrm{~m}($ slope $<20 \%)$ \\
linear point-to-point error) & $<4 \mathrm{~m}($ slope $>20 \%)$ \\
\hline
\end{tabular}

Table 3: Specification of DEMs used for comparison

\begin{tabular}{|c|c|c|c|c|}
\hline & SRTM1 & $\begin{array}{l}\text { ASTER } \\
\text { GDEM2 }\end{array}$ & $\begin{array}{c}\text { Ries Crater } \\
\text { (DGM10) }\end{array}$ & $\begin{array}{c}\text { Meteor Crater } \\
\text { (NCALM) }\end{array}$ \\
\hline Pixel posting & $30 \mathrm{~m}$ & $30 \mathrm{~m}$ & $10 \mathrm{~m}$ & $1 \mathrm{~m}$ \\
\hline \multicolumn{5}{|l|}{ Absolute accuracy } \\
\hline horizontal & $20 \mathrm{~m}$ & $30 \mathrm{~m}$ & $\pm 0.5-2 \mathrm{~m}$ & $0.03-0.70 \mathrm{~m}$ \\
\hline vertical & $16 \mathrm{~m}$ & $17 \mathrm{~m}$ & $\pm 0.5-2 \mathrm{~m}$ & $0.05-0.30 \mathrm{~m}$ \\
\hline \multicolumn{5}{|l|}{ Datum } \\
\hline horizontal & WGS84 & WGS84 & ETRS89 & NAD83 \\
\hline vertical & EGM96 & EGM96 & DHHN92 & NAVD88 \\
\hline
\end{tabular}


PostPrint Version: Meteoritics \& Planetary Science, 52/7, 2017

Table 4: Impact crater DEM comparison.

\begin{tabular}{rccc}
\hline \hline Crater \& DEM & $\begin{array}{c}\text { Minimum } \\
\text { Elevation }(\mathrm{m})\end{array}$ & $\begin{array}{c}\text { Maximum } \\
\text { Elevation }(\mathrm{m})\end{array}$ & $\begin{array}{c}\text { Mean Elevation } \\
(\mathrm{m})\end{array}$ \\
\hline Meteor (Fig. 3) & & & \\
NCALM & 1553.0 & 1757.7 & $1683.0 \pm 22.2$ \\
TanDEM-X & 1557.5 & 1747.6 & $1680.2 \pm 22.5$ \\
SRTM & 1561 & 1742 & $1682.6 \pm 19.3$ \\
ASTER & 1544 & 1748 & $1679.2 \pm 22.4$
\end{tabular}

Henbury (Fig. 5)

$\begin{array}{rccc}\text { TanDEM-X } & 430.8 & 530.3 & 453.9 \pm 13.9 \\ \text { SRTM } & 424 & 526 & 452.1 \pm 13.9 \\ \text { ASTER } & 416 & 545 & 460.8 \pm 16.9\end{array}$

Amguid (Fig. 5)

$\begin{array}{rccc}\text { TanDEM-X } & 482.6 & 816.2 & 660.6 \pm 83.9 \\ \text { SRTM } & 496 & 817 & 660.2 \pm 83.4 \\ \text { ASTER } & 493 & 825 & 659.6 \pm 83.6\end{array}$

Wolfe Creek (Fig. 5)

$\begin{array}{rccc}\text { TanDEM-X } & 322.6 & 382.5 & 346.6 \pm 9.2 \\ \text { SRTM } & 326 & 378 & 348.2 \pm 9.1 \\ \text { ASTER } & 308 & 379 & 342.0 \pm 10.2\end{array}$

Ries (Fig. 7)

$\begin{array}{rccc}\text { DGM10 } & 391.7 & 667.6 & 481.3 \pm 54.6 \\ \text { TanDEM-X } & 365.4 & 690.6 & 483.7 \pm 56.9 \\ \text { SRTM } & 392 & 672 & 483.5 \pm 56.6 \\ \text { ASTER } & 338 & 674 & 478.2 \pm 57.4\end{array}$

Beyenchime-Salaatin (Fig. 10)

$\begin{array}{rccc}\text { TanDEM-X } & 95.9 & 256.6 & 170.9 \pm 30.6 \\ \text { ASTER } & 48 & 287 & 159.2 \pm 30.3\end{array}$

Popigai (Fig. 11)

\begin{tabular}{rccc} 
TanDEM-X & 0.0 & 542.3 & $165.7 \pm 111.1$ \\
ASTER & 20 & 563 & $157.5 \pm 110.1$ \\
\hline
\end{tabular}




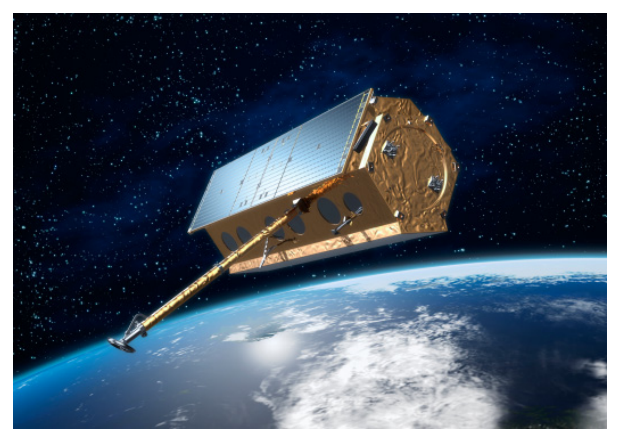

Fig. 1: Artist's view of the TerraSAR-X X-band radar satellite.

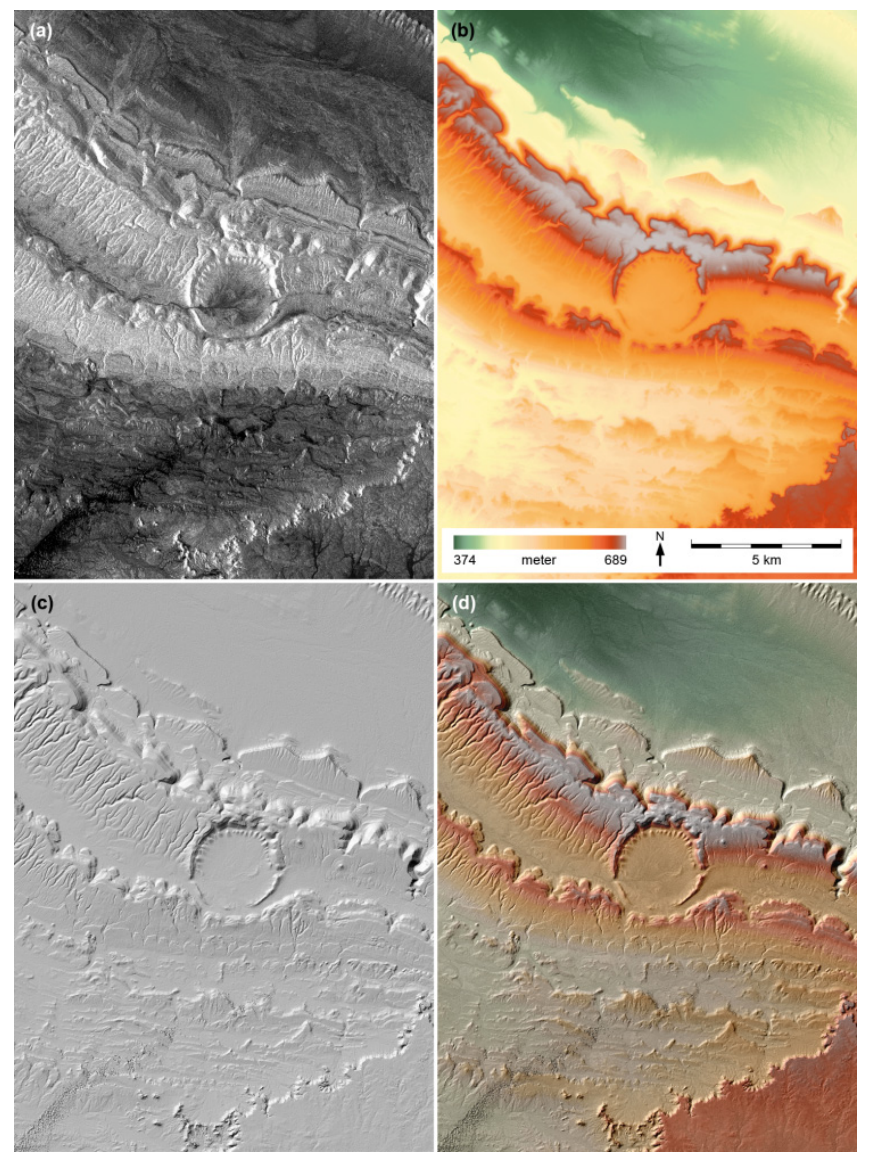

Fig. 2: Four steps in the TanDEM-X DEM analysis of terrestrial impact craters for the example of Ouarkziz: (a) X-band radar amplitude, (b) color-coded digital elevation data, (c) hillshaded greyscale map after illumination with a Sun at $45^{\circ}$ elevation and $315^{\circ}$ azimuth, (d) hillshaded color-coded DEM with underlying X-band radar amplitude signal. 

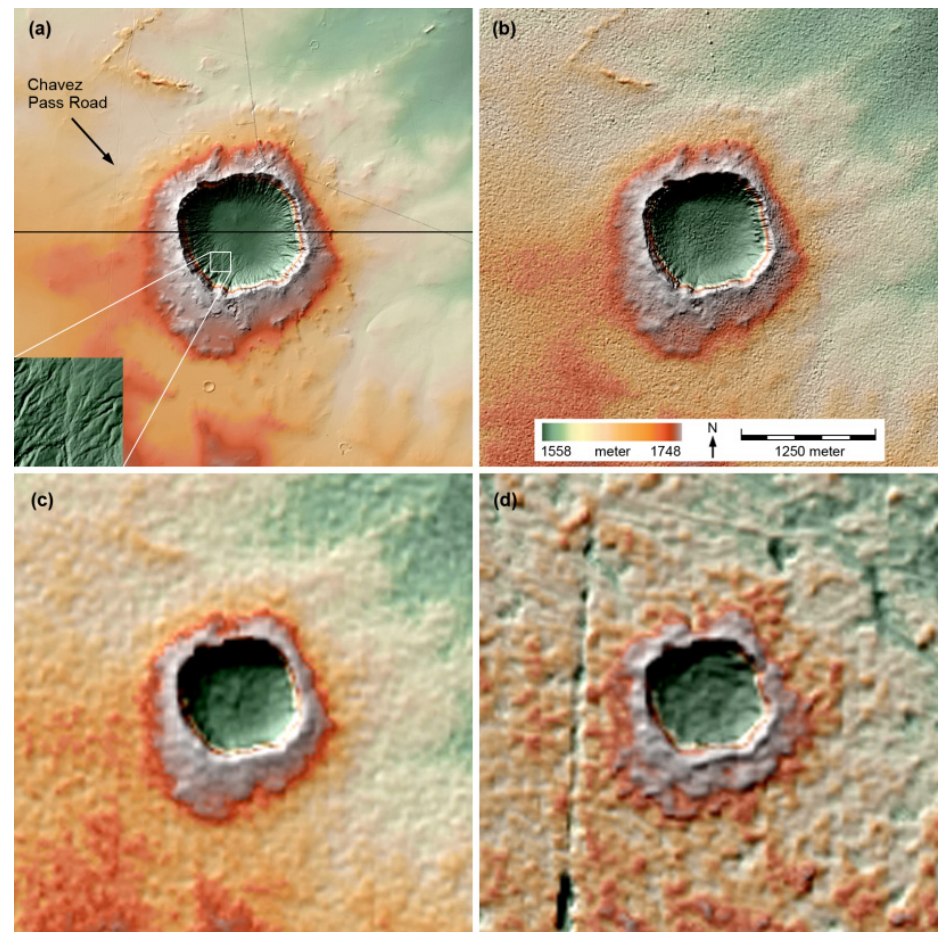

Fig. 3: Meteor crater $\left(\right.$ lat $=35^{\circ} 02^{\prime} \mathrm{N}$, long $\left.=111^{\circ} 01^{\prime} \mathrm{W}, \varnothing=1.18 \mathrm{~km}\right)$, mapped by four DEMs: (a) NCALM LiDAR, (b) TanDEM-X, (c) SRTM1, (d) ASTER GDEM V2. Crater size is scaled to TanDEM$X$. The inset in (a) shows the full resolution of NCALM. The horizontal line in (a) indicates the location of the west-east transect from Fig. 4.
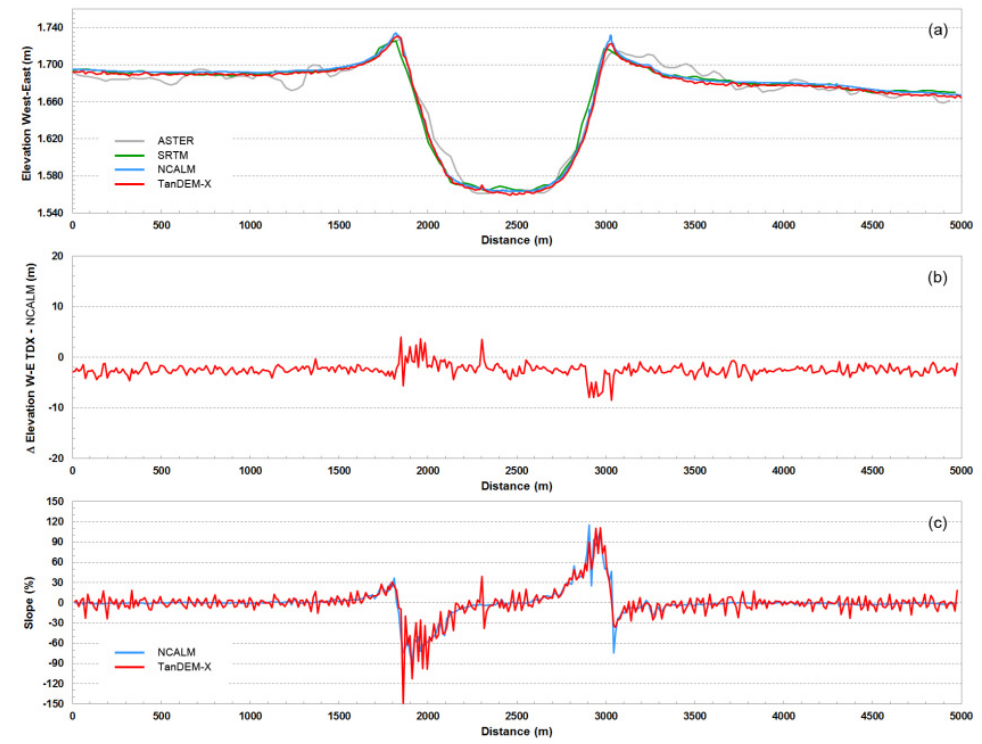

Fig. 4: (a): West-east elevation profiles of Meteor crater based on the four DEMs of Fig. 3. (b): Elevation difference along profile between TanDEM-X and NCALM LiDAR. (c): Slope along elevation profile for TanDEM-X and NCALM LIDAR. 

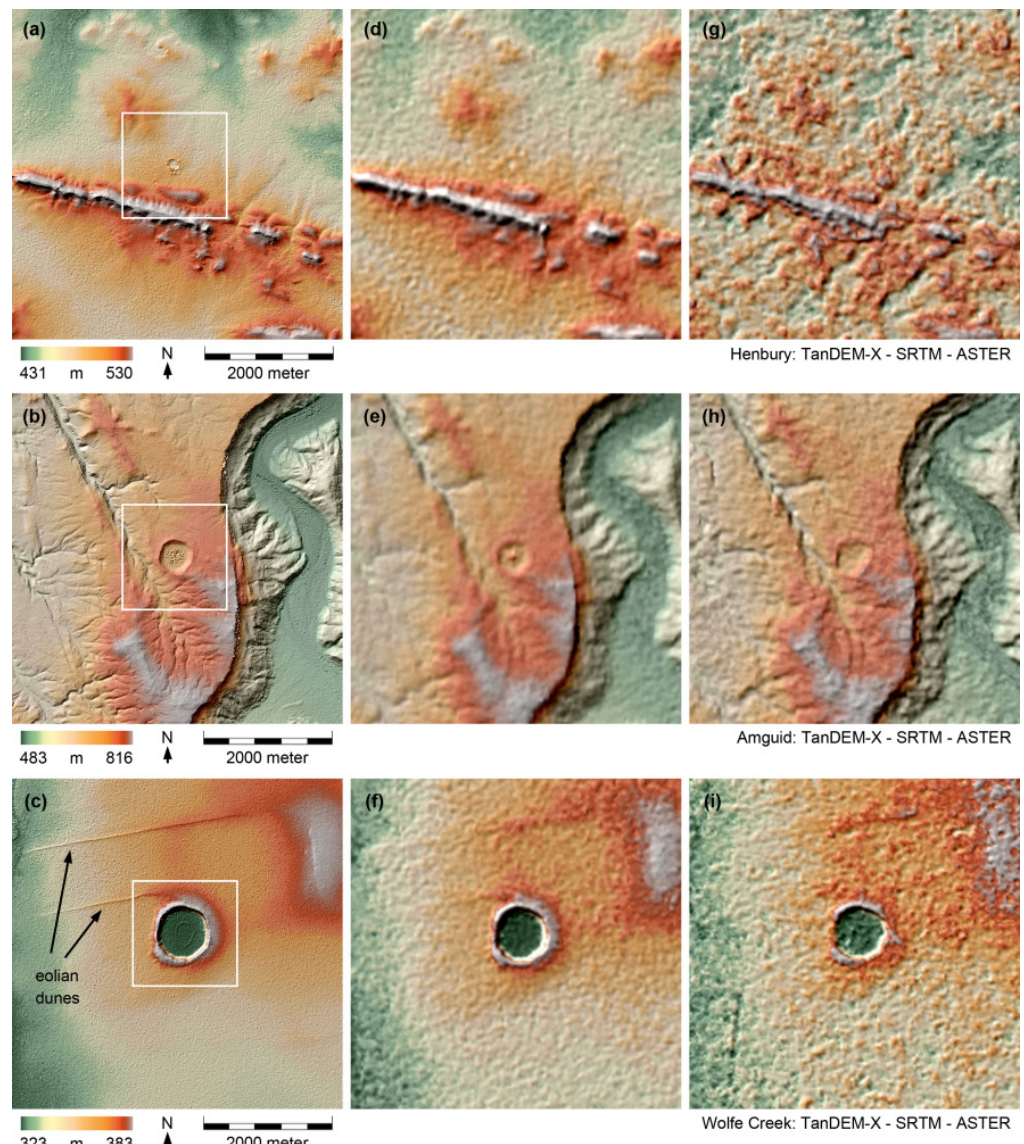

Fig. 5: Hillshaded DEM maps for three representative small craters. Henbury crater field (top row, lat $=24^{\circ} 34^{\prime} \mathrm{N}$, long $=133^{\circ} 08^{\prime} \mathrm{E}, \varnothing=7-180 \mathrm{~m}$ ), Amguid (middle row, lat $=26^{\circ} 05^{\prime} \mathrm{N}$, long $=4^{\circ} 23^{\prime} \mathrm{E}$, $\varnothing=450 \mathrm{~m}$ ) and Wolfe Creek (bottom row, lat $=19^{\circ} 10^{\prime} \mathrm{S}$, long $=127^{\circ} 48^{\prime} \mathrm{E}, \varnothing=880 \mathrm{~m}$ ) with TanDEM-X DEM (a-c), SRTM1 DEM (d-f) and ASTER GDEM V2 ( $g-i)$. The inset in the TanDEM-X maps illustrates the scenes imaged in Fig. 6.
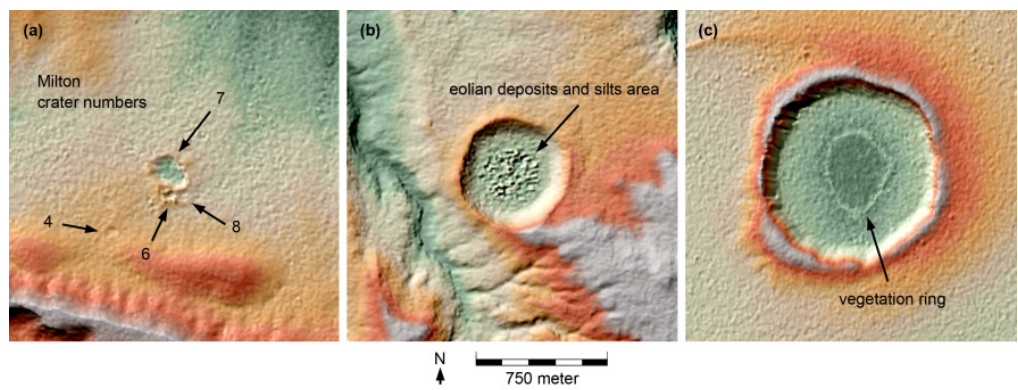

Fig. 6: Color adjusted close-ups for Henbury (a), Amguid (b) and Wolfe Creek (c), derived from the hillshaded TanDEM-X DEM maps in Fig. 5 showing morphological detail even for small craters. 

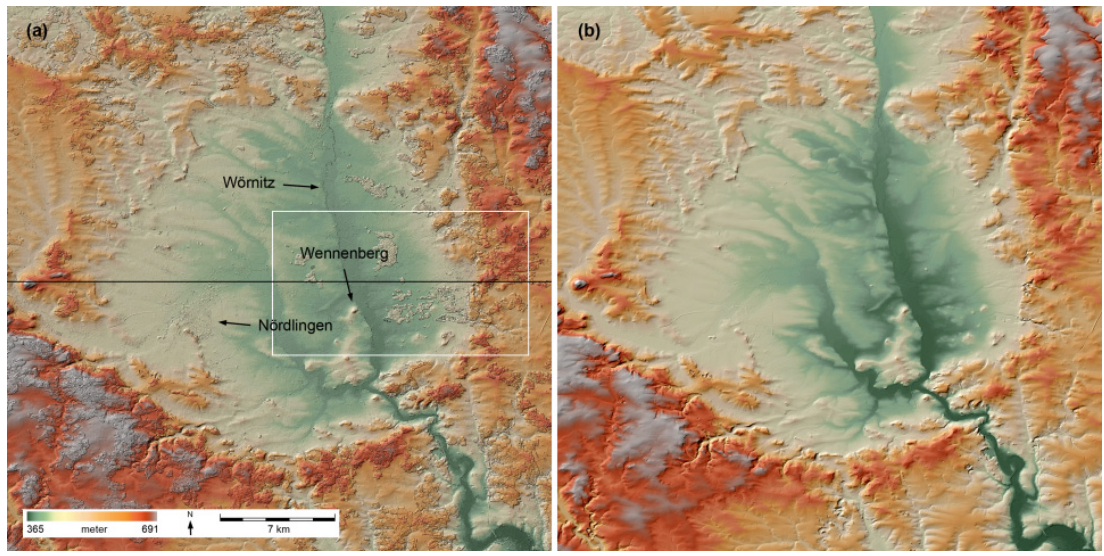

Fig. 7: Hillshaded DEM of the Ries crater (lat $=48^{\circ} 53^{\prime} \mathrm{N}$, long $=10^{\circ} 37^{\prime} \mathrm{E}, \varnothing=24 \mathrm{~km}$ ) using TanDEM$X$ data (a) and DGM10 based on LiDAR scanning (b). The inset in (a) identifies the area displayed in Fig. 8 with the horizontal line in (a) specifying where the elevation profile from Fig. 9 was extracted.

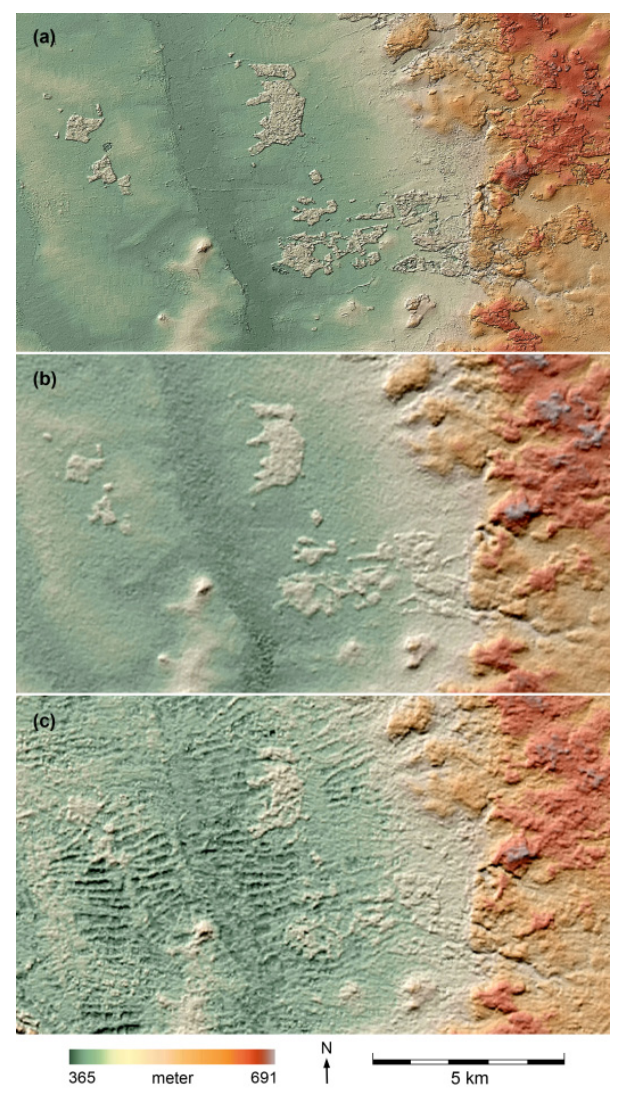

Fig. 8: A section of the Ries imaged with full TanDEM-X DEM resolution (a) in comparison to SRTM1 (b) and ASTER GDEM V2 (c). Small patches of woodland are scattered over the scene. 


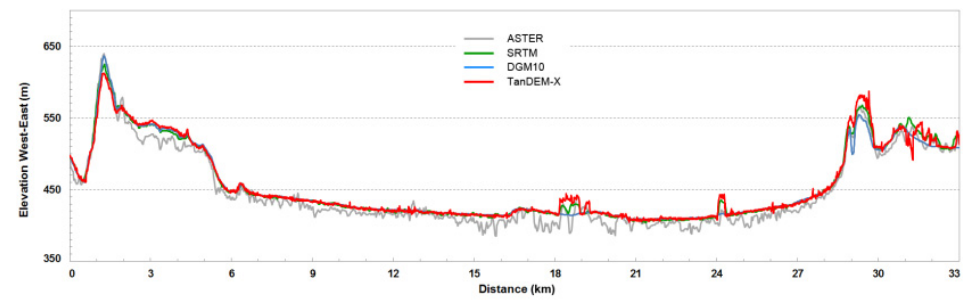

Fig. 9: West-east elevation profile through the Ries crater based on the four available DEMs (TanDEM-X, DGM10, SRTM1 and ASTER GDEM V2).

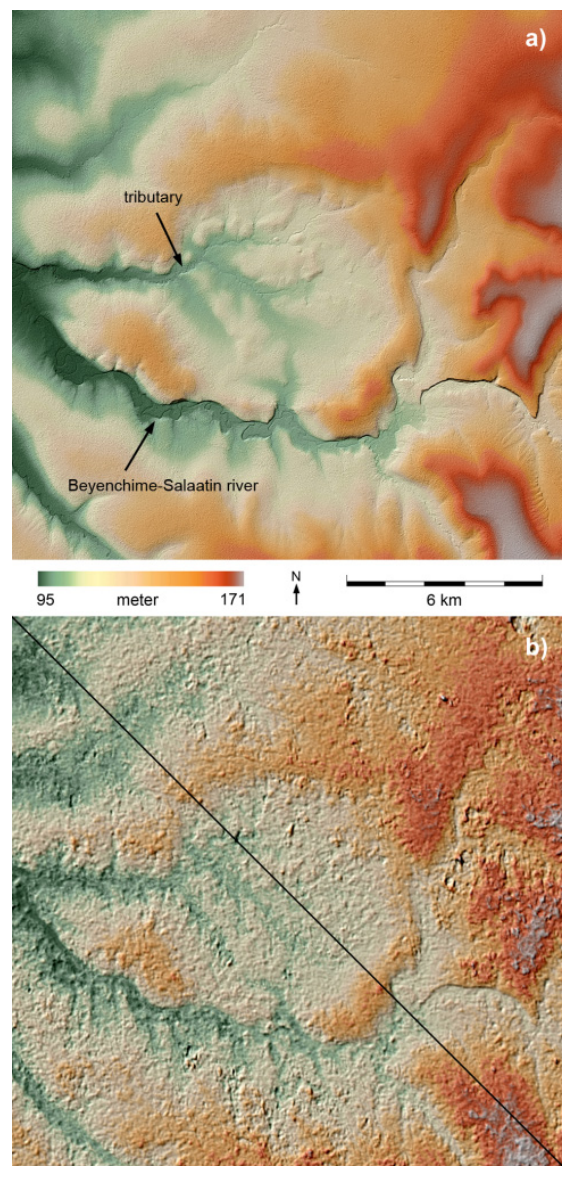

Fig. 10: The hillshaded map of Beyenchime-Salaatin (lat $=71^{\circ} 03^{\prime} \mathrm{N}, 121^{\circ} 41^{\prime} \mathrm{E}, \varnothing=8 \mathrm{~km}$ ) derived from TanDEM-X data (a) with the ASTER GDEM V2 (b) for comparison. The diagonal line in (b) shows the location of the northwest-southeast transect from Fig. 12a. 


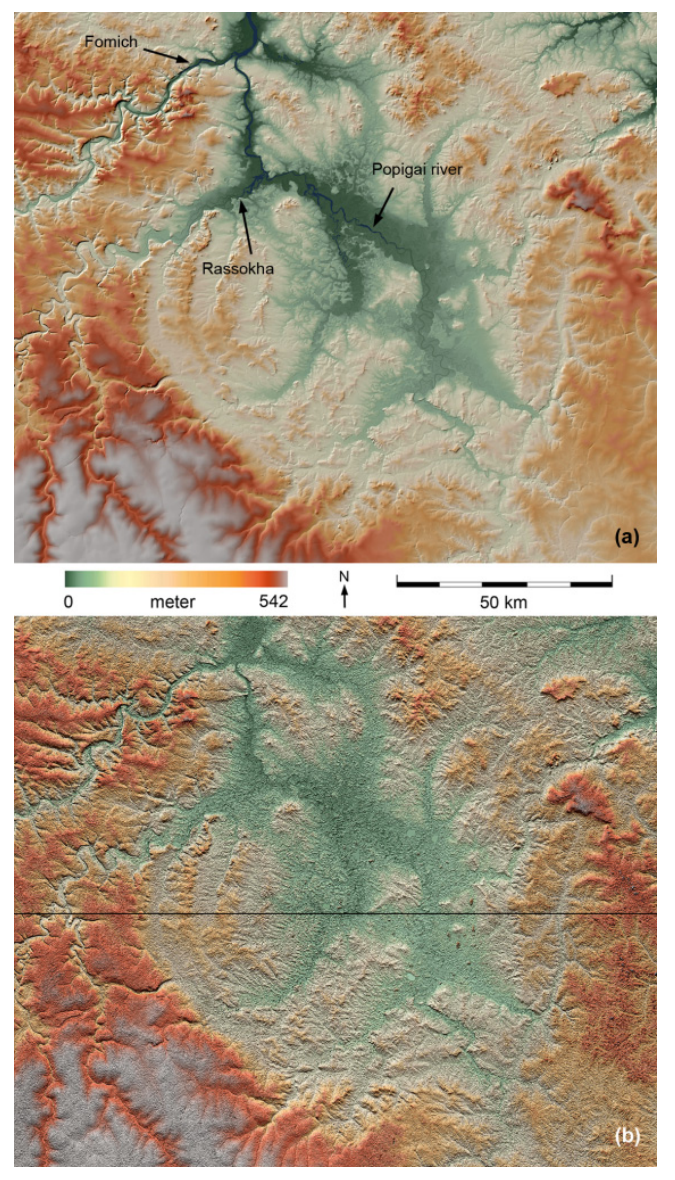

Fig. 11: The Popigai structure (lat $=71^{\circ} 39^{\prime} \mathrm{N}$, long $=111^{\circ} 11^{\prime} \mathrm{E}, \varnothing=100 \mathrm{~km}$ ) in Siberia as seen in TanDEM-X DEM data (a) with ASTER GDEM V2 (b) for comparison. The horizontal line in (b) shows the location of the west-east transect from Fig. 12b.
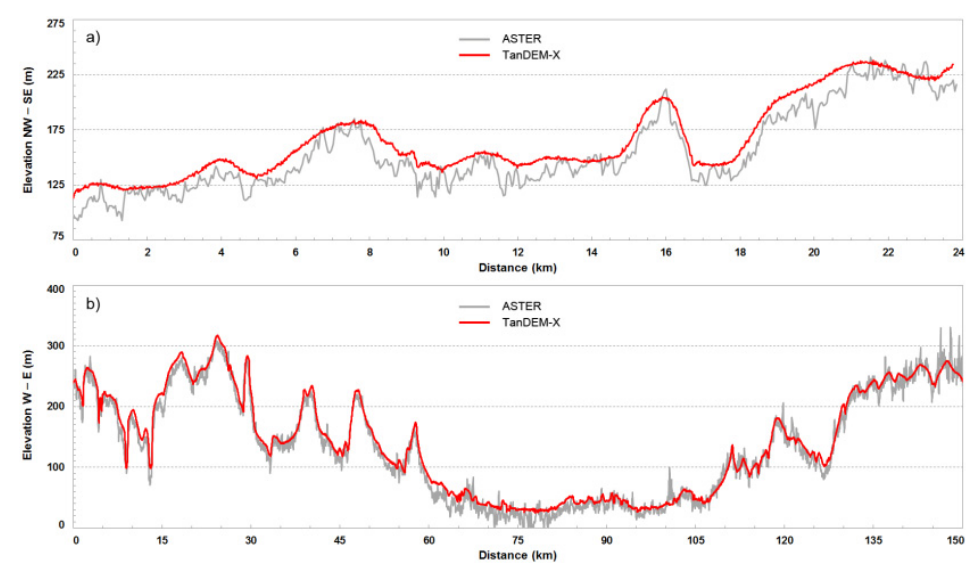

Fig. 12: Elevation profiles through Beyenchime-Salaatin (a) and Popigai (b) as derived from TanDEM$\mathrm{X}$ and ASTER DEM data. 